\title{
An analysis of the processing of intramodal and intermodal time intervals
}

\author{
Leila Azari ${ }^{1}$ - Giovanna Mioni ${ }^{2} \cdot$ Robert Rousseau $^{1} \cdot$ Simon Grondin $^{1}$ \\ Published online: 18 November 2019 \\ (C) The Psychonomic Society, Inc. 2019
}

\begin{abstract}
In this 3-experiment study, the Weber fractions in the 300-ms and 900-ms duration ranges are obtained with 9 types of empty intervals resulting from the combinations of three types of signals for marking the beginning and end of the signals: auditory (A), visual (V), or tactile (T). There were three types of intramodal intervals (AA, TT, and VV) and 6 types of intermodal intervals (AT, AV, VA, VT, TA, and TV). The second marker is always the same during Experiments 1 (A), 2 (V), and 3 (T). With an uncertainty strategy where the first marker is 1 of 2 sensory signals being presented randomly from trial to trial, the study provides direct comparisons of the perceived length of the different marker-type intervals. The results reveal that the Weber fraction is nearly constant in the three types of intramodal intervals, but is clearly lower at $900 \mathrm{~ms}$ than at $300 \mathrm{~ms}$ in intermodal conditions. In several cases, the intramodal intervals are perceived as shorter than intermodal intervals, which is interpreted as an effect of the efficiency in detecting the second marker of an intramodal interval. There were no significant differences between the TA and VA intervals (Experiment 1) and between the AV and TV intervals (Experiment 2), but in Experiment 3, the AT intervals were perceived as longer than the VT intervals. The results are interpreted in terms of the generalized form of Weber's law, using the properties of the signals for explaining the additional nontemporal noise observed in the intermodal conditions.
\end{abstract}

Keywords Temporal Processing · Time perception · Sensory modalities

In order to study time perception scientifically, it is necessary to delineate somehow, with sensory signals, a given temporal extent to be estimated. In return, it is necessary to assess the impact on time perception of the choice of sensory signals used to mark time intervals. The aim of this paper is to contribute to this assessment. Two critical dependent variables could serve to assess the relative impact of sensory markers: one is related to sensitivity, and the other to perceived duration.

It is generally admitted that the processing of temporal information is more efficient when intervals to be estimated are marked by auditory rather than by visual signals. For the discrimination of short, empty time intervals, the difference threshold is much lower when the two brief signals marking the intervals are auditory instead of visual (Grondin,

Simon Grondin

simon.grondin@psy.ulaval.ca

1 École de Psychologie, Université Laval, 2325 rue des Bibliothèques, Québec G1V 0A6, Canada

2 Dipartimento di Psicologia Generale, Università di Padova, Padova, Italy
Gamache, Tobin, Bisson, \& Hawke, 2008; Grondin, Ouellet, \& Roussel, 2001, 2004), and this is also true with filled intervals (Grondin, 1993; Mioni, Grassi, et al., 2016a) - that is, when a single signal marks the beginning and end of the interval.

As for perceived duration, several older articles on the topic report that intervals are perceived as longer in the auditory modality than in the visual one (Behar \& Bevan, 1961; Goldstone \& Goldfarb, 1964; Goldstone \& Lhamon, 1972, 1974). More recent demonstrations led to the same conclusion (Gamache \& Grondin, 2010; Penney, Gibbon, \& Meck, 2000; Wearden, Edwards, Fakhri, \& Percival, 1998; Ulrich, Nitschke, \& Rammsayer, 2006). Note that this effect seems to fade when empty intervals are used (Grondin, 2005).

Of specific interest in the present study are the cases of empty intervals. In addition to the comparison of intervals marked by two brief auditory (A) versus two brief visual (V) signals, or even versus two brief tactile (T) signals (intervals referred to here as intramodal), the comparisons will also involve intermodal intervals (i.e., intervals marked by a combination of A,V, and T signals : AV, AT, VA, VT, TA, TV).

The difficulty in discriminating the duration of brief intermodal intervals, compared with intramodal intervals, is well 
established when auditory and visual combinations are used (Fraisse, 1952; Hocherman \& Ben-Dov, 1979; R. Rousseau \& Kristofferson, 1973; R. Rousseau, Poirier, \& Lemyre, 1983). The difficulty is extended to cases involving tactile markers when intervals last $250 \mathrm{~ms}$ (Grondin \& Rousseau, 1991), but fades when intervals last $1,000 \mathrm{~ms}$ and involves a combination of $\mathrm{A}$ and $\mathrm{T}$ intervals (see Grondin, 2003). Although this intermodality effect is robust with very brief intervals, some factors may contribute to reducing it. For instance, take a design in which three successive 20-ms signals (A or V) mark two empty intervals to be discriminated, the middle marker indicating the offset of the first interval and the onset of the second interval. Discrimination will be better with three A signals, but will not be better with three $\mathrm{V}$ signals than with a VAV sequence (Kuroda, Hasuo, Labonté, Laflamme, \& Grondin, 2014). Using explicit counting during the discrimination of 1,600-ms intervals may also reduce the difference between the VV and AV conditions (Grondin et al., 2004).

The difference between the discrimination levels in intramodal versus intermodal conditions remains an elusive problem. Likely influenced by the Gestalt principles, Fraisse (1952) suggested that this difference is due to the possibility that intramodal intervals benefit from some organization between successive signals that are similar. This makes sense if we consider that increasing the difference in frequency of the two auditory signals marking an interval, therefore decreasing the quality of the organization, will reduce the discrimination level (van Noorden, 1975). However, it remains difficult to understand why some intramodal versus intermodal differences fade rapidly with longer intervals; and it is also difficult to understand why not only the discrimination of VV sequences, but also that of VA sequences (Grondin, Roussel, Gamache, Roy, \& Ouellet, 2005), is impaired when the second marker is lengthened (quality of organization decreased) if the benefit of organization belongs to intramodal intervals.

Grondin and Rousseau (1991) posit rather that there is a possibility to benefit from a specific temporal process within each modality. In intramodal conditions, each modality would assume the processing of temporal information. However, when intervals are intermodal, the processing would be based on the involvement of what they referred to as an aspecific process (i.e., not modality specific). Indeed, in the timing literature, it is most often assumed that there is an internal, central ("modality aspecific") clock for processing temporal information. This internal clock is typically described as a pacemaker-counter mechanism (Block \& Zakay, 2008; Gibbon, Church, \& Meck, 1984; Ulrich et al., 2006). The pacemaker emits pulses that are accumulated in a counter, and the estimation of time is based on the amount of pulses accumulated. A classical model of this sort is the scalar expectancy theory (Gibbon, 1977).

Other researchers rather posit that the auditory cortex has a supramodal role in the processing of temporal information.
Within such a perspective, the lower performance level in vision than in audition is attributed to the need to transfer the visual signals into an auditory code (Kanai, Lloyd, Bueti, \& Walsh, 2011; see Bueti, 2011). With such an explanation, having one auditory signal (AV or VA conditions) as is the case with an intermodal interval instead of none (VV) should lead to performance levels in between the ones involving two auditory signals, or two visual signals. However, clearly, when $\mathrm{A}$ and $\mathrm{V}$ signals are used, discrimination of very brief intervals $(<1 \mathrm{~s})$ is much lower in $\mathrm{AV}$ and VA conditions than in AA and VV conditions (Grondin \& Rousseau, 1991; Rousseau et al., 1983; for a brief review of the theoretical importance of intermodality issues, see Grondin, 2014b).

There is less literature on the comparison of the perceived duration of different types of intermodal intervals, or on the comparison of intramodal versus intermodal intervals. Mayer, Di Luca, and Ernst (2014) assessed the relative duration of pairs of intermodal intervals using auditory filled intervals as a basis of comparison. While they found no difference between the VT and TV conditions, AT intervals were perceived as longer than TA intervals, just like AV intervals were perceived as longer than VA intervals (see also Grondin, Ivry, Franz, Perreault, \& Metthé, 1996). There are even fewer reports of the comparison for the perceived duration of intramodal versus intermodal intervals. We know, for instance, that when brief (circa $250 \mathrm{~ms}$ ) AA, TA, and VA intervals are presented randomly, $\mathrm{TA}$ is perceived as much longer than $\mathrm{AA}$, and that AA is perceived as much longer than VA (Grondin \& Rousseau, 1991). Indeed, in this study, when the first marker of an intermodal interval was marked by a tactile signal, it resulted in more "long" responses.

The purpose of the present study is to provide direct comparisons of the Weber fractions obtained with three types of intramodal intervals (AA, TT, and VV) and six types of intermodal intervals based on the combinations of the $\mathrm{A}, \mathrm{T}$, and $\mathrm{V}$ signals used for marking intramodal intervals. The Weber fraction is the difference threshold divided by the standard duration tested. The fractions will be estimated in the 300ms and 900-ms duration ranges (standard durations). It will provide a first direct comparison of the stability of the Weber fraction for these nine marker-type conditions. Testing the stability of the Weber fraction (Weber's law) is most important in the study of time perception considering that the scalar property (constancy of the Weber fraction) is a crucial feature of classical pacemaker-counter models in the field. What is known in psychophysics is that the Weber fraction might not remain constant when judgments are made on low magnitudes. This feature can be accounted for by a generalized form of Weber's law. In the case of a central timing process, it means that the part of nontemporal variance in the discrimination process is important for brief intervals, but should fade when intervals to be discriminated are longer. The present study will be a test of this potential decrease of the Weber 
fraction from 300-ms to 900-ms conditions. A systematic decrease of the difference in the Weber fraction values between the intramodal versus intermodal conditions at $900 \mathrm{~ms}$ would be consistent with the generalized form of the Weber's law, and therefore consistent with a central clock hypothesis.

The study is also designed to provide direct comparisons of the perceived length of the different marker-type intervals. These direct comparisons will be based on an uncertainty strategy (Grondin \& Rousseau, 1991) where the second marker of an interval is always the same in a block of trials, but where the first marker is one of two sensory signals, these signals being presented randomly from trial to trial. Over the course of three experiments, each type of intermodal interval will be compared with the other eight interval types. It is expected from this investigation to get a larger picture of the discrimination levels in all marker-type conditions, and to get additional information about the properties of the signals, A, $\mathrm{T}$, and $\mathrm{V}$, as the first or second marker, and about their contribution to the nontemporal variance observed in the interval discrimination process. The investigation is based on the adoption of the temporal bisection task. With this method, a judgment is made after each presentation of an interval, and it is possible to manipulate uncertainty as in Grondin and Rousseau (1991), and it is also possible to have an estimate of the discrimination threshold (which was not the case for Grondin and Rousseau, who used only one short and one long intervals) and, therefore, of the Weber fraction.

\section{General method}

\section{Apparatus and stimuli}

All experimental tasks were computerized. The tasks included visual, auditory, and tactile stimuli and required motor responses. All tasks were programmed and controlled by EPrime 2.0, installed on a Lenovo computer, model 7360PC7. The screen size of the Lenovo ThinkVision monitor was 34.3$\mathrm{cm}$ high by $36-\mathrm{cm}$ wide, and its resolution was $1,055 \times 980$. Participants, who were seated in a dimly lit room, responded either "short" or "long" by pressing either 1 or 3, respectively, on a Lenovo wired SK-8825 keyboard.

The visual stimuli were produced using a circular red-lightemitting diode (LED: Radio-Shack \#276-088) that was placed about $1 \mathrm{~m}$ in front of the participant, with a visual angle of about 0.57 degrees. The auditory stimuli were $1-\mathrm{kHz}$ tones with an intensity recorded at about $70 \mathrm{~dB}$ SPL. These signals were presented by the speakers that were located at 1 meter from the participants. The tactile signals were provided through electrocutaneous stimulation. Electrodes were installed on both the left and right hands of the subjects. The electric stimulus was generated by a source emitting constant pulses with a frequency between 70 and $110 \mathrm{~Hz}$. Since the calibration of the stimulation was adjusted according to the subjective perception of the participant, its power (intensity) could be different for each participant. A gel was used to improve the electrical conductivity between the electrodes and participants' hands.

These visual (V), auditory (A), and tactile (T) stimuli were all easily detectable and lasted $20 \mathrm{~ms}$. Two successive stimuli were used in each trial in order to mark the empty duration to be judged. There were three types of intramodal interval conditions, AA, VV, and TT, and six types of intermodal conditions, AV, AT, VA, VT, TA, and TV. Within each experiment, there were three types of intervals, one intramodal and two intermodal. In the procedure below, used to describe the content of each experiment, markers' modalities will be described with $\mathrm{X}, \mathrm{Y}$ and $\mathrm{Z}$.

\section{Procedure}

A bisection task was used in each of the three experiments of the study. In each experiment, the second marker was fixed, say $\mathrm{X}$, and the first marker was either $\mathrm{X}$ and $\mathrm{Y}$ (in one uncertainty condition), $\mathrm{X}$ and $\mathrm{Z}$ (in a second uncertainty condition), or $\mathrm{Y}$ and $\mathrm{Z}$ (in a third uncertainty condition). The three experiments correspond to three different fixed-marker conditions, $\mathrm{X}$, Y, or Z.

There were eight sessions in each experiment, including four sessions for each of two standard duration conditions: $300 \mathrm{~ms}$ and $900 \mathrm{~ms}$. The comparison interval values for the 300-ms condition were 200, 240, 280, 320, 360, and $400 \mathrm{~ms}$. The comparison interval values for the 900 -ms condition were three times longer: $600 ; 720 ; 840 ; 960 ; 1,080$; and 1,200 ms.

In each experiment, there were "certainty" and "uncertainty" conditions. In the certainty condition (Sessions 1 and 5 of each experiment), participants were informed of the sensory mode used for both markers for the complete block of trials. In the uncertainty condition, participants knew the sensory mode of only the second marker. The first marker could be delivered from one of two sensory modes, the two potential modes always remaining the same for a complete session.

For the certainty condition, there were five presentations at the beginning of each block of the shortest and the longest intervals of the distribution (200 ms and $400 \mathrm{~ms}$ for the 300 ms standard condition, or $600 \mathrm{~ms}$ and 1,200 ms for the $900-\mathrm{ms}$ standard condition). There were six blocks, with two consecutive blocks having the same marker-type condition. Within each block, there were 12 presentations of each of the comparison intervals in a random order (72 trials per block). Overall, there were 24 repetitions of six intervals for each marker-type interval (XX-XY-XZ), for a total 432 trials. If Session 1 was dedicated to the $300-\mathrm{ms}$ condition, Session 5 was dedicated to the 900-ms condition (and vice versa).

Sessions 2-4 and 6-8 were dedicated to the uncertainty condition. Each uncertainty session started with the five 
presentations of the shortest and the longest comparison intervals in each of two marker-type intervals used in the block. The experiment included four identical blocks; each block consisted of six presentations of each of the two marker-type intervals involved in the session. In this case, there were 72 trials per block (total $=288$ trials). If Sessions $2-4$ were dedicated to the 300-ms condition, Sessions 5-8 were dedicated to the 900-ms condition (and vice versa).

\section{Data analyses}

For each experimental condition of each experiment, the probability of responding that the interval is closer to the long than to the short standard interval was computed. From this measurement, a psychometric function was plotted for each participant in each condition. Each of six points of the function is based on 24 observations. Each psychometric function is adjusted to a nonlinear regression whose parameters are estimated from the cumulative normal distribution function. Two parameters are then extracted from each psychometric function: the mean $(\mu)$, which represents the point of subjective equality (PSE), and the standard deviation $(\sigma)$, which is the estimate of the difference threshold.

The PSE can be described as the $x$ value corresponding to the 0.50 probability of "longer" responses on the $y$-axis (Grondin, 2008). Using the PSE makes it possible to directly compare the perceived duration in two different modality conditions. From the PSE, we can also calculate another dependent variable, the constant error $(\mathrm{CE})$ : $\mathrm{CE}=$ standard $-\mathrm{PSE}$. Using the constant error rather than the PSE as the dependent variable allows the comparison of the perceived duration of the standard conditions, the short (300 ms) and long (900 ms). Defined this way (standard - PSE), it facilitates the analysis of the data as a higher $\mathrm{CE}$ value means more long responses (duration perceived as longer).

The Weber fraction is the other crucial dependent variable of this study: it is the difference threshold divided by the standard value (300 or 900). A high Weber fraction corresponds to low sensitivity. Weber fraction can be used to calculate sensitivity to stimuli of different magnitudes - namely, in this study, 300 and $900 \mathrm{~ms}$.

In each experiment, for each of two dependent variables of interest, the Weber fraction and the constant error, a series of three repeated-measure factorial ANOVAs, 2 (duration: 300, $900) \times 2$ (certainty, uncertainty) $\times 2$ (marker-type condition) was performed. Note that in the certainty condition, the Weber fraction and constant error of each marker-type condition (XX, XY, and XZ) were estimated only once, but were used twice in an ANOVA (and occurred twice in the figures). In the uncertainty condition, the $\mathrm{XX}, \mathrm{XY}$, and $\mathrm{XZ}$ were estimated twice (XX vs. $\mathrm{XY}$; $\mathrm{XX}$ vs. $\mathrm{XZ}$; $\mathrm{XY}$ vs. $\mathrm{XZ}$ ). Each estimate was used only once in an ANOVA (and occurred only once in the figures). An alpha level of .05 has been used throughout the analyses.

\section{Experiment 1: Fixed marker is auditory}

\section{Method}

In this first experiment, the second marker is always auditory: performances in the AA, TA, and VA conditions are compared.

\section{Participants}

Twelve students, 19 to 39 years of age ( $M=26.58$, eight female) volunteered from Laval University and were paid $\$ 56$ (\$7 for each of the eight sessions of each experiment) for their participation.

\section{Procedure}

In Sessions 1 and 5, there were two consecutive blocks of AA, two of TA, and two of VA in the certainty condition. For half of the participants, Sessions 1-4 were dedicated to the 300-ms standard condition, and Sessions 5-8 to the 900-ms standard condition; for the other half of participants, the order was reversed. The order of the marker-type condition within a session was counterbalanced across participants. Sessions $2-$ 4 and 6-8 were dedicated to the uncertainty condition, one session for each three "compared pairs of marker-type conditions" at $300 \mathrm{~ms}$, and one session for each of three "compared pairs of marker-type conditions" at 900 ms: AA versus TA, AA versus VA, and TA versus VA.

Table 1 Goodness-of-fit of the individual psychometric functions: median and mean $R^{2}$ values, and number of $R^{2}$ values $>.90$ in each of the eight sessions of Experiment 1

\begin{tabular}{llll}
\hline & Median & Mean & Number $>.90$ \\
\hline 1. AA vs. TA vs. VA certain $300 \mathrm{~ms}$ & .962 & .920 & 24 out of 36 \\
2. AA vs. TA uncertain $300 \mathrm{~ms}$ & .956 & .962 & 20 out of 24 \\
3. AA vs. VA uncertain $300 \mathrm{~ms}$ & .970 & .940 & 19 out of 24 \\
4. TA vs. VA uncertain $300 \mathrm{~ms}$ & .911 & .886 & 15 out of 24 \\
5. AA vs. TA vs. VA certain $900 \mathrm{~ms}$ & .980 & .956 & 30 out of 36 \\
6. AA vs. TA uncertain $900 \mathrm{~ms}$ & .976 & .951 & 22 out of 24 \\
7. AA vs. VA uncertain $900 \mathrm{~ms}$ & .965 & .953 & 20 out of 24 \\
8. TA vs. VA uncertain $900 \mathrm{~ms}$ & .970 & .956 & 20 out of 24 \\
\hline
\end{tabular}




\section{Results}

Table 1 gives an overview of the goodness-of-fit of the individual psychometric functions in each of the eight sessions of Experiment 1.

\section{Weber fraction}

Conditions AA versus TA Figure 1 (upper panel) shows the mean Weber fraction in the AA and TA conditions, at 300 and $900 \mathrm{~ms}$, in the certainty and uncertainty conditions. An ANOVA reveals that there are significant main effects for modality, $F(1,11)=44.167, p<.05, \eta_{\mathrm{p}}^{2}=0.801$, and for duration, $F(1,11)=6.995, p<.05, \eta_{p}^{2}=0.389$. The Weber fraction in AA $(M=.121)$ was lower than in TA $(M=.329)$. The Weber fraction, however, was higher at $300 \mathrm{~ms}(M=.253)$ than at $900 \mathrm{~ms}(M=.197)$. There was also a significant interaction between modality and duration, $F(1,11)=11.943, p<.05, \eta_{p}^{2}=0.521$. There was no significant simple main effect for the Weber fraction in AA (300 ms: .107 vs. 900 ms: .136). There was, however, a significant simple main effect of duration in TA. The
Weber fraction in TA at $300 \mathrm{~ms}(M=.400)$ was higher than at $900 \mathrm{~ms}$.

Conditions AA versus VA Figure 1 (middle panel) shows the mean Weber fraction in the AA and VA conditions, at 300 and $900 \mathrm{~ms}$, in the certainty and uncertainty conditions. An ANOVA reveals that there are significant main effects for modality, $F(1,11)=21.115, p<.05, \eta_{\mathrm{p}}^{2}=0.657$, and duration, $F(1,11)=4.860, p<.05, \eta_{\mathrm{p}}^{2}=4.306$. The Weber fraction in AA $(M=.131)$ is lower than in VA $(M=.341)$. There was also a significant interaction between modality and duration, $F(1$, $11)=27.855, p<.05, \eta_{\mathrm{p}}^{2}=0.717$. The Weber fractions in AA at $300 \mathrm{~ms}(M=.106)$ and $900 \mathrm{~ms}(M=.155)$ were not significantly different, but in VA it was significantly higher at $300 \mathrm{~ms}(M=.424)$ than at $900 \mathrm{~ms}(M=.259)$.

Conditions TA versus VA Figure 1 (lower panel) shows the mean Weber fraction in the VA and TA conditions, at 300 and $900 \mathrm{~ms}$, in the certainty and uncertainty conditions. An ANOVA reveals that there is a significant main effect for duration, $F(1,11)=43.310, p<.05, \eta_{\mathrm{p}}^{2}=0.797$. The Weber fraction at $300 \mathrm{~ms}$ was higher $(M=.418)$ than at $900 \mathrm{~ms}(M=$ $.225)$. No other main or interaction effect was significant.
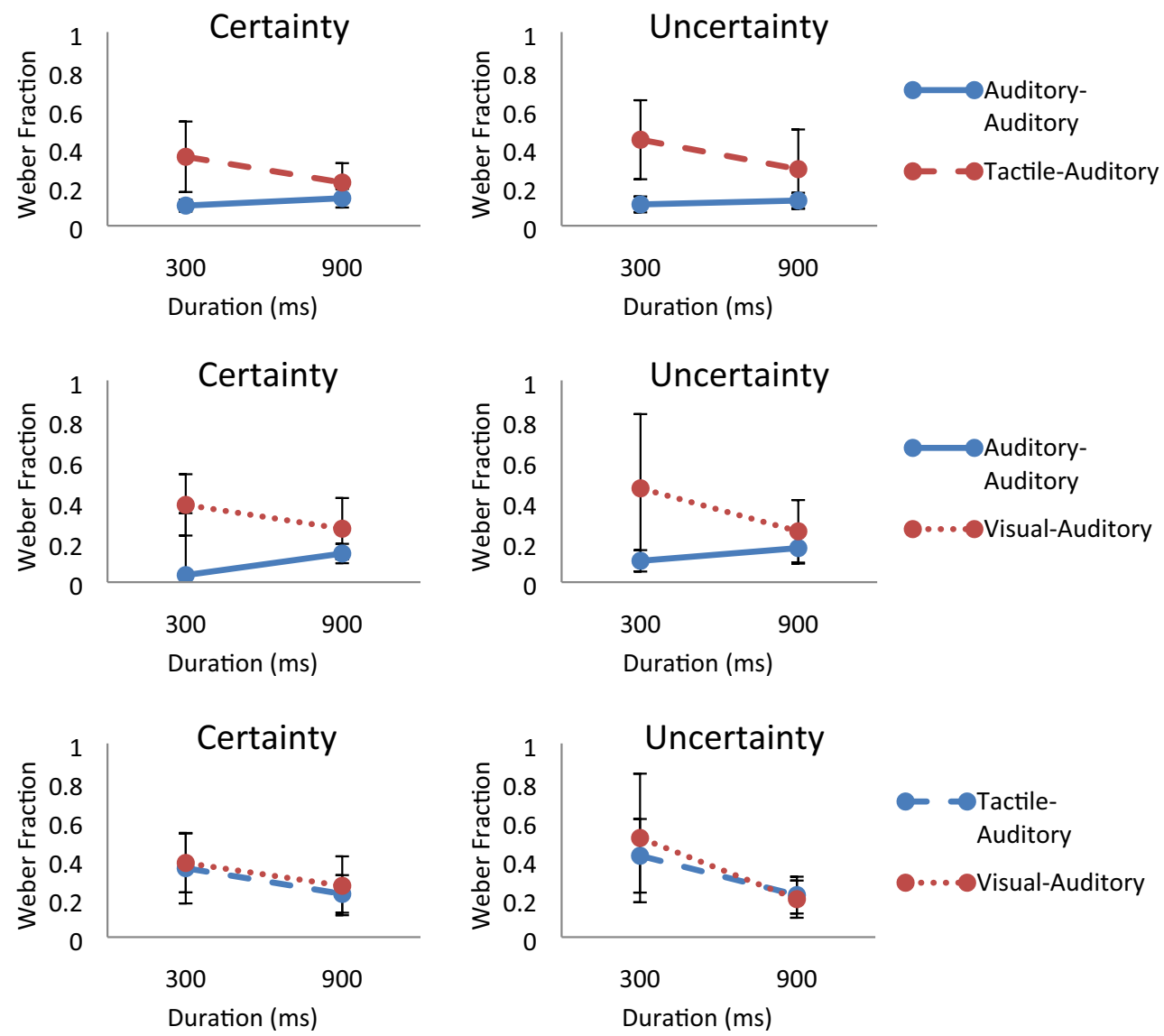

Fig. 1 Weber fraction in the AA versus TA (upper panel), AA versus VA (middle panel), and TA versus VA (lower panel) conditions under the certainty and uncertainty conditions in Experiment 1. Bars represent the standard error 


\section{Constant error}

Conditions AA versus TA Figure 2 (upper panel) shows the mean constant error in the AA and TA conditions, at 300 and $900 \mathrm{~ms}$, in the certainty and uncertainty conditions. An ANOVA reveals that there is a significant main effect for modality, $F(1,11)=14.373, p<.05, \eta_{\mathrm{p}}^{2}=0.566$. The constant error in AA was lower $(M=-12.276)$ than in TA $(M=$ 26.303). No other main or interaction effect was significant.

Conditions AA versus VA Figure 2 (middle panel) shows the mean constant error in the AA and VA conditions, at 300 and $900 \mathrm{~ms}$, in the certainty and uncertainty conditions. An ANOVA reveals that there is a significant main effect for certainty, $F(1,11)=5.683, p<.05, \eta_{\mathrm{p}}^{2}=0.341$. The constant error was higher under uncertainty $(M=31.557)$ than under certainty $(M=2.771)$. There was a significant three-way interaction between modality, certainty, and duration, $F(1,11)=$ 5.281, $p<.05, \eta_{\mathrm{p}}^{2}=0.324$. Under uncertainty, there was a significant interaction between modality and duration, $F(1$, 11) $=6.041, p<.05, \eta_{\mathrm{p}}^{2}=0.354$. Under uncertainty, the constant error at $300 \mathrm{~ms}$ was lower in AA $(M=-9.055)$ than in VA $(M=43.723)$. At $900 \mathrm{~ms}$, however, the constant error was higher in AA $(M=75.504)$ than VA $(M=.252)$. Under certainty, the constant error at $300 \mathrm{~ms}$ was lower in AA $(M=$ $-11.176)$ than VA $(M=30.402)$. At $900 \mathrm{~ms}$ also, the constant error was lower in AA $(M=-19.552)$ than VA $(M=11.741)$.

Conditions TA versus VA Figure 2 (lower panel) shows the mean constant error in the VA and TA conditions, at 300 and $900 \mathrm{~ms}$, in the certainty and uncertainty conditions. An ANOVA reveals no significant main or interaction effect.

\section{Discussion of Experiment 1}

In this experiment, there is a clear difference in the discrimination levels between the intramodal condition (AA) and the intermodal ones (VA and TA). The better discrimination level of AA intervals remains robust under the certainty and uncertainty conditions, and although the effect is much stronger at $300 \mathrm{~ms}$, it is still present at $900 \mathrm{~ms}$. In the certainty and both uncertainty cases, the Weber fraction in the intramodal

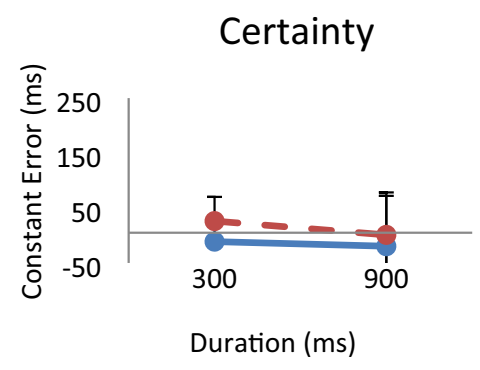

Certainty

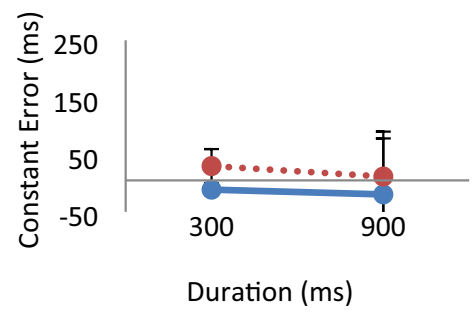

Certainty

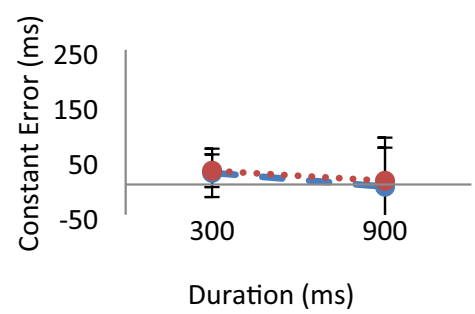

Uncertainty

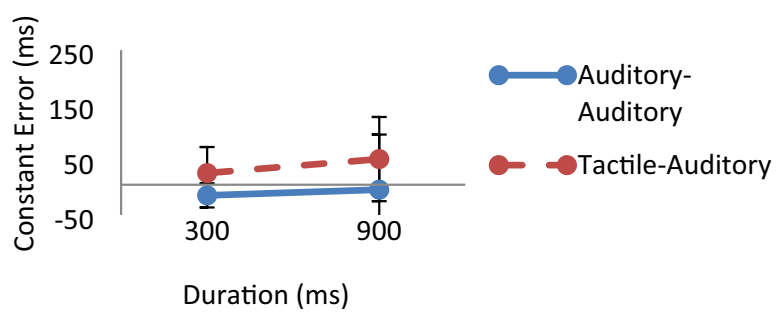

Uncertainty

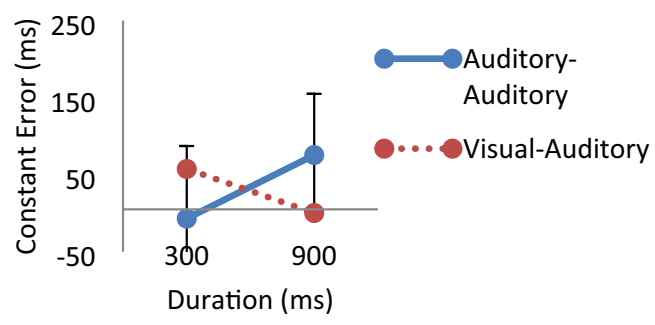

Uncertainty

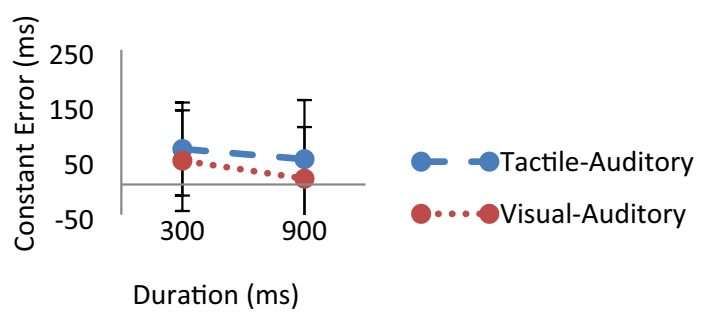

Fig. 2 Constant error in the AA versus TA (upper panel), AA versus VA (middle panel), and TA versus VA (lower panel) conditions under certainty and uncertainty conditions in Experiment 1. Bars represent the standard error 
condition is even lower at 300 than at $900 \mathrm{~ms}$. This repeated tendency is indeed consistent with the fact that this fraction, with empty auditory intervals, was reported to be lower at $200 \mathrm{~ms}$ than at 1,000 ms (Grondin, 2010).

In the intermodal conditions, the decrease of the Weber fraction from 300 to $900 \mathrm{~ms}$ is consistent with the generalized law of Weber. The higher fraction with briefer intervals would be due to the contribution of nontemporal variance, relative to the time-based variance, in the timing process. Note that in Rousseau et al. (1983), the difference between the VA and intramodal conditions remained much higher at 1,000 ms. The results also reveal that the modality of the first marker did not influence the discrimination level of the intermodal intervals (TA versus VA; see Fig. 3). This finding is consistent with what was reported by Mayer et al. (2014) and by Grondin and Rousseau (1991). Finally, the results also reveal that the uncertainty placed on the sensory provenance of the first marker does not affect the discrimination level.

As for the constant error, the AA intervals are perceived as shorter than the TA intervals, and this effect does not interact with duration. This finding is consistent with what is reported in Grondin and Rousseau (1991); in this article, the certainty versus uncertainty condition was restricted to the $250-\mathrm{ms}$ intervals. Quite surprisingly, when TA and VA intervals are directly compared, there is no significant effect on the constant error; and even looking at a condition close to that of Grondin and Rousseau (at $300 \mathrm{~ms}$ in the uncertainty condition), there is a strong sign of a difference in perceived duration. In Grondin and Rousseau, when the second marker is A and the first marker $\mathrm{A}, \mathrm{V}$, or $\mathrm{T}$, the probability of responding that an inter$\mathrm{val}$ is long is .48 in AA, .33 in VA, and .63 in TA.

\section{Experiment 2: Fixed marker is visual}

\section{Method}

In this second experiment, the second marker is always visual: performances in the $\mathrm{VV}, \mathrm{AV}$, and TV conditions are compared.

\section{Participants}

Twelve students, 19 to 39 years of age ( $M=29.58,10$ female), volunteered from Laval University and were paid $\$ 56$ ( $\$ 7$ for each of the eight sessions of each experiment) for their participation.
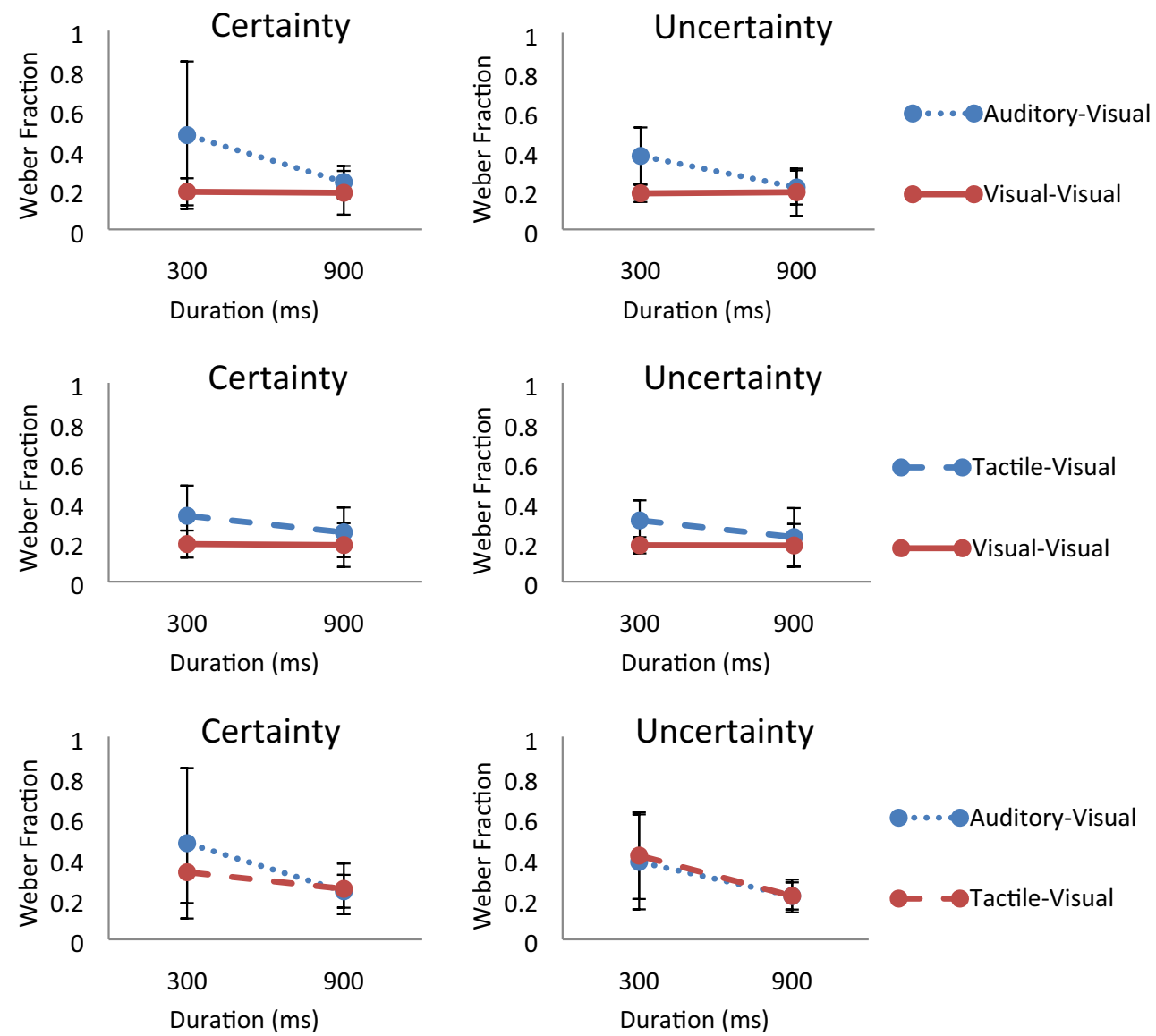

Fig. 3 Weber fraction in the VV versus AV (upper panel), VV versus TV (middle panel), and AV versus TV (lower panel) conditions under the certainty and uncertainty conditions in Experiment 2. Bars represent the standard error 


\section{Procedure}

In Sessions 1 and 5, there were two consecutive blocks of VV, two of AV and two of TV in the certainty condition. For half of the participants, Sessions 1-4 were dedicated to the 300-ms standard condition, and Sessions 5-8 to the 900-ms standard condition; for the other half of participants, the order was reversed. The order of the marker-type condition within a session was counterbalanced across participants. Sessions $2-$ 4 and 6-8 were dedicated to the uncertainty condition, one session for each three "compared pairs of marker-type conditions" at $300 \mathrm{~ms}$, and one session for each of three "compared pairs of marker-type conditions" at $900 \mathrm{~ms}$ : AV versus TV, AV versus VV, and TV versus VV.

\section{Results}

Table 2 shows an overview of the goodness-of-fit of the individual psychometric functions in each of the eight sessions of Experiment 2.

\section{Weber fraction}

Conditions VV versus AV Figure 3 (upper panel) shows the mean Weber fraction in the VV and VA conditions, at 300 and $900 \mathrm{~ms}$, in the certainty and uncertainty conditions. An ANOVA reveals that there is a significant main effect for modality, $F(1,11)=26.841, p<.05, \eta_{p}^{2}=.709$, and duration, $F(1,11)=9.119, p<.05, \eta_{\mathrm{p}}^{2}=.453$. The Weber fraction was higher in $\mathrm{AV}(M=.324)$ than in VV $(M=.186)$. There was also a significant interaction between modality and duration, $F(1,11)=7.355, p<.05, \eta_{\mathrm{p}}^{2}=.401$. Modality effect was significant at $300 \mathrm{~ms}$, but not at $900 \mathrm{~ms}$. At $300 \mathrm{~ms}$, Weber fraction was higher in $\mathrm{AV}(M=.423)$ than in VV $(M=.186)$.

Conditions VV versus TV Figure 3 (middle panel) shows the mean Weber fraction in the VV and TV conditions, at 300 and

Table 2 Goodness-of-fit of the individual psychometric functions: median and mean $R^{2}$ values, and number of $R^{2}$ values $>.90$ in each of the eight sessions of Experiment 2

\begin{tabular}{lccc}
\hline & Median & Mean & Number $>.90$ \\
\hline 1. VV vs. AV vs. TV certain $300 \mathrm{~ms}$ & .948 & .928 & 27 out of 36 \\
2. VV vs. TV uncertain $300 \mathrm{~ms}$ & .965 & .947 & 21 out of 24 \\
3. VV vs. AV uncertain $300 \mathrm{~ms}$ & .958 & .931 & 17 out of 24 \\
4. AV vs. TV uncertain $300 \mathrm{~ms}$ & .920 & .917 & 17 out of 24 \\
5. VV vs. TV vs. TV certain $900 \mathrm{~ms}$ & .976 & .957 & 32 out of 36 \\
6. VV vs. TV uncertain $900 \mathrm{~ms}$ & .966 & .949 & 21 out of 24 \\
7. VV vs. AV uncertain $900 \mathrm{~ms}$ & .985 & .961 & 20 out of 24 \\
8. AV vs. TV uncertain $900 \mathrm{~ms}$ & .977 & .960 & 22 out of 24 \\
\hline
\end{tabular}

$900 \mathrm{~ms}$, in the certainty and uncertainty conditions. An ANOVA reveals that there is a significant main effect for modality, $F(1,11)=21.073, p<.05, \eta_{\mathrm{p}}^{2}=.657$. The Weber fraction in TV was higher $(M=.278)$ than in VV $(M=.184)$. There was also a significant interaction between modality and duration, $F(1,11)=5.515, p<.05, \eta_{\mathrm{p}}^{2}=.334$. The Weber fraction was significantly higher in TV $(M=.320)$ than in $\mathrm{VV}(M=.186)$ at $300 \mathrm{~ms}$, but not at $900 \mathrm{~ms}$. The analysis also reveals the stability of the Weber fraction over time in $\mathrm{VV}$, but not in TV.

Conditions AV versus TV Figure 2 (lower panel) shows the mean Weber fraction in the AV and TV conditions, at 300 and $900 \mathrm{~ms}$, in the certainty and uncertainty conditions. An ANOVA reveals that there is a significant main effect for duration, $F(1,11)=10.138, p<.05, \eta_{\mathrm{p}}^{2}=.480$. The Weber fraction at $300 \mathrm{~ms}$ was higher $(M=.400)$ than at $900 \mathrm{~ms}(M=$ .229). There was no other significant main or interaction effect.

\section{Constant error}

Conditions VV versus AV Figure 4 (upper panel) shows the mean constant error in the VV and VA conditions, at 300 and $900 \mathrm{~ms}$, in the certainty and uncertainty conditions. An ANOVA reveals that there is a significant main effect for modality, $F(1,11)=15.141, p<.05, \eta_{\mathrm{p}}^{2}=.579$. The constant error in $\mathrm{AV}(M=81.915)$ was higher than in VV $(M=34.646)$. There was also a significant interaction between modality and duration, $F(1,11)=11.563, p<.05, \eta_{\mathrm{p}}^{2}=.512$. At $300 \mathrm{~ms}$, the constant error in $\mathrm{AV}(M=77.008)$ was higher than in $\mathrm{VV}(M=$ $-2.660)$.

Conditions VV versus TV Figure 4 (middle panel) shows the mean constant error in the VV and TV conditions, at 300 and $900 \mathrm{~ms}$, in the certainty and uncertainty conditions. An ANOVA reveals that there is a significant main effect for modality, $F(1,11)=17.360, p<.05, \eta_{p}^{2}=.612$. The constant error in TV $(M=74.133)$ was higher than in VV $(M=38.695)$. There was a significant interaction between modality and duration, $F(1,11)=18.041, p<.05, \eta_{\mathrm{p}}^{2}=.621$. At $300 \mathrm{~ms}$, the constant error in TV $(M=62.760)$ was higher than in VV $(M=$ $-1.345)$, but there was no such difference between TV $(M=$ $85.505)$ and VV $(M=78.735)$ at $900 \mathrm{~ms}$.

Conditions AV versus TV Figure 4 (lower panel) shows the mean constant error in the AV and TV conditions, at 300 and $900 \mathrm{~ms}$, in the certainty and uncertainty conditions. An ANOVA reveals that there is no significant main or interaction effect. 
Certainty

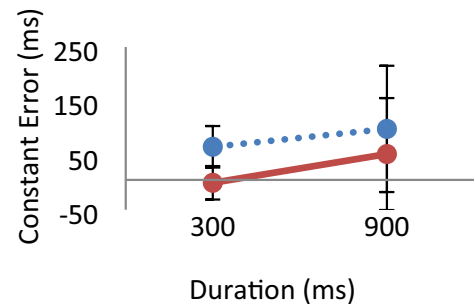

Certainty

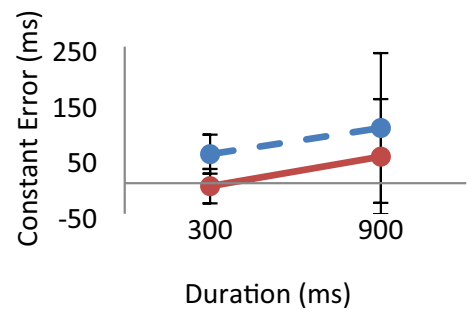

Certainty

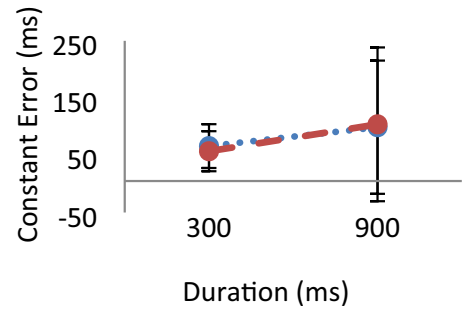

Uncertainty

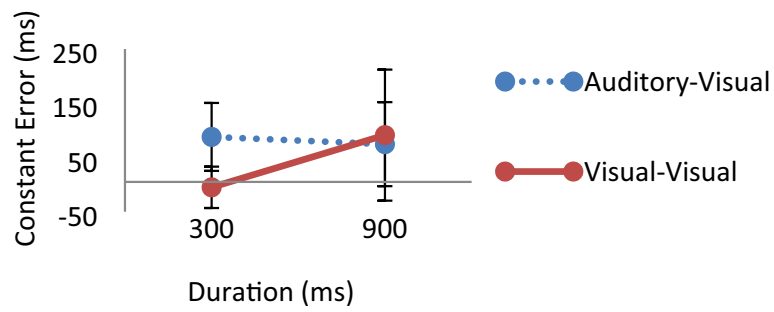

Uncertainty

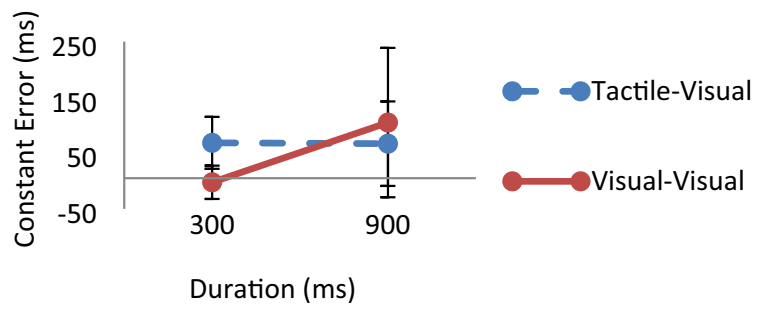

Uncertainty

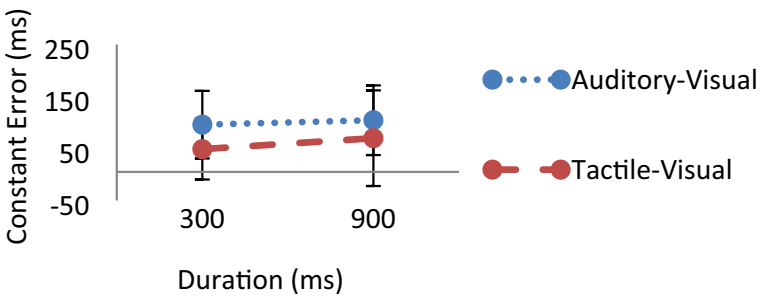

Fig. 4 Constant error (in ms) in the VV versus AV (upper panel), VV versus TV (middle panel), and AV versus TV (lower panel) conditions under the certainty and uncertainty conditions in Experiment 2. Bars represent the standard error

\section{Discussion of Experiment 2}

As for Experiment 1, there was a Duration $\times$ Modality interaction in both conditions involving one intramodal and one intermodal interval. There is some stability of the Weber fraction in VV from 300 to $900 \mathrm{~ms}$, but there is a significant decrease of the Weber fraction in AV and TV conditions. This decrease was observed in both the certainty and uncertainty conditions. Moreover, when AV and TV conditions are directly compared, the performance levels in these conditions do not differ, but once again, in both cases, there is a significant decrease of the Weber fraction from 300 to $900 \mathrm{~ms}$. Once again, adding Uncertainty about the sensory mode of the first marker did not result in poorer discrimination. There was no difference between the certainty and uncertainty conditions.

As for the constant error, it is interesting that in the certainty condition, participants responded more often long in $\mathrm{AV}$ and in TV than in VV. Because this occurred in the certainty condition, the effect cannot be attributable to a direct comparison of intramodal versus intermodal conditions. In the uncertainty condition, the difference between the VV condition and the intermodal ones fades at $900 \mathrm{~ms}$. Finally, as in Experiment 1, when both intermodal intervals are compared, there is no significant difference for the constant error. In Grondin and Rousseau (1991), a direct comparison of AV, TV, and VV intervals with an uncertainty on the modality of the first marker resulted in more long responses in TV than in VV or AV.

\section{Experiment 3: Fixed marker is tactile}

\section{Method}

In this third experiment, the second marker is always tactile: performances in the TT, AT, and VT conditions are compared.

\section{Participants}

Twelve participants, 19 to 39 years of age $(M=29.83$, seven female), volunteered students from Laval University were paid $\$ 56$ ( $\$ 7$ for each of the eight sessions of each experiment) for their participation. 


\section{Procedure}

In Sessions 1 and 5, there were two consecutive blocks of TT, two of AT, and two of VT in the certainty condition. For half of the participants, Sessions 1-4 were dedicated to the 300-ms standard condition, and Sessions 5-8 to the 900-ms standard condition; for the other half of participants, the order was reversed. The order of the marker-type condition within a session was counterbalanced across participants. Sessions 24 and 6-8 were dedicated to the uncertainty condition, one session for each three "compared pairs of marker-type conditions" at $300 \mathrm{~ms}$, and one session for each of three "compared pairs of marker-type conditions" at $900 \mathrm{~ms}$ : AT versus TT, AT versus VT, and TT versus VT.

\section{Results}

Table 3 shows an overview of the goodness-of-fit of the individual psychometric functions in each of the eight sessions of Experiment 3.

\section{Weber fraction}

Conditions TT versus AT Figure 5 (upper panel) shows the mean Weber fraction in the TT and AT conditions, at 300 and $900 \mathrm{~ms}$, in the certainty and uncertainty conditions. An ANOVA reveals that there are main effects for modality, $F(1$, $11)=42.982, p<.05, \eta_{\mathrm{p}}^{2}=.796$, for Certainty, $F(1,11)=$ 6.439, $p<.05, \eta_{\mathrm{p}}^{2}=.369$, and for duration: $F(1,11)=$ 14.361, $p<.05, \eta_{\mathrm{p}}^{2}=.566$. The Weber fraction in AT $(M=$ $.301)$ is higher than in TT $(M=.170)$. The Weber fraction is lower for certainty $(M=.211)$ than for uncertainty $(M=.260)$, and is higher at $300 \mathrm{~ms}(M=.277)$ than at $900 \mathrm{~ms}(M=.194)$. There was a significant interaction between modality and duration, $F(1,11)=7.492, p<.05, \eta_{\mathrm{p}}^{2}=.405$. The Weber fraction in AT is higher at $300(M=.380)$ than at $900 \mathrm{~ms}(M=.223)$,

Table 3 Goodness-of-fit of the individual psychometric functions: median and mean $R^{2}$ values, and number of $R^{2}$ values $>.90$ in each of the 8 sessions of Experiment 3

\begin{tabular}{llll}
\hline & Median & Mean & Number $>.90$ \\
\hline 1. TT vs. AT vs. VT certain $300 \mathrm{~ms}:$ & .948 & .936 & 31 out of 36 \\
2. TT vs. AT uncertain $300 \mathrm{~ms}$ & .975 & .926 & 18 out of 24 \\
3. TT vs. VT uncertain $300 \mathrm{~ms}$ & .953 & .934 & 15 out of 24 \\
4. AT vs. VT uncertain $300 \mathrm{~ms}$ & .920 & .913 & 15 out of 24 \\
5. TT vs. AT vs. VT certain $900 \mathrm{~ms}$ & .970 & .946 & 29 out of 36 \\
6. TT vs. AT uncertain $900 \mathrm{~ms}$ & .970 & .936 & 20 out of 24 \\
7. TT vs. VT uncertain $900 \mathrm{~ms}$ & .956 & .953 & 22 out of 24 \\
8. AT vs. VT uncertain $900 \mathrm{~ms}$ & .962 & .950 & 21 out of 24 \\
\hline
\end{tabular}

which is not the case in TT $(M=.174$ at $300 \mathrm{~ms}$; and $M=$ .166 at $900 \mathrm{~ms})$.

Conditions TT versus VT Figure 5 (middle panel) shows the mean Weber fraction in the TT and VT conditions, at 300 and $900 \mathrm{~ms}$, in the certainty and uncertainty conditions. An ANOVA reveals that there are significant main effects for modality, $F(1,11)=51.613, p<.05, \eta_{\mathrm{p}}^{2}=.824$, and for duration, $F(1,11)=19.179, p<.05, \eta_{\mathrm{p}}^{2}=.64$. The Weber fraction is lower in TT $(M=.169)$ than in VT $(M=.297)$, and is higher at $300 \mathrm{~ms}(M=.266)$ than at $900 \mathrm{~ms}(M=.200)$. There was also a significant interaction between modality and duration, $F(1,11)=11.426, p<.05, \eta_{\mathrm{p}}^{2}=.510$. In TT, there is no significant difference between the Weber fraction at $300(M$ $=.171)$ and $900 \mathrm{~ms}(M=.164)$, but in VT, the fraction is significantly higher at $300(M=.359)$ than at $900 \mathrm{~ms}(M=$ .236).

Conditions AT versus VT Figure 5 (lower panel) shows the mean Weber fraction in the AT and VT conditions, at 300 and $900 \mathrm{~ms}$, in the certainty and uncertainty conditions. An ANOVA reveals that there is a significant duration effect, $F(1$, $11)=9.819, p<.05, \eta_{p}^{2}=.472$. The Weber fraction is higher at $300 \mathrm{~ms}(M=.336)$ than at $900 \mathrm{~ms}(M=.238)$.

\section{Constant error}

Conditions TT versus AT Figure 6 (upper panel) shows the mean constant error in the TT and AT conditions, at 300 and $900 \mathrm{~ms}$, in the certainty and uncertainty conditions. An ANOVA reveals that there is a significant main effect for modality, $F(1,11)=4.702, p<.053, \eta_{\mathrm{p}}^{2}=.299$. The constant error in AT $(M=54.791)$ is higher than in TT $(M=10.723)$. No other significant main or interaction effect was significant.

Conditions TT versus VT Figure 6 (middle panel) shows the mean constant error in the TT and VT conditions, at 300 and $900 \mathrm{~ms}$, in the certainty and uncertainty conditions. An ANOVA reveals that there is a significant main effect for certainty, $F(1,11)=6.621, p<.05, \eta_{p}^{2}=.376$. The constant error is lower for certainty $(M=16.340)$ than for uncertainty $(M=45.933)$.

Conditions AT versus VT Figure 6 (lower panel) shows the mean constant error in the AT and VT conditions, at 300 and $900 \mathrm{~ms}$, in the certainty and uncertainty conditions. An ANOVA reveals that there are significant main effects for modality, $F(1,11)=36.546, p<.05, \eta_{\mathrm{p}}^{2}=.769$, and certainty, $F(1$, $11)=7.975, p<.05, \eta_{\mathrm{p}}^{2}=.420$. The constant error in AT $(M=$ $80.268)$ is higher than in VT $(M=28.798)$. The constant error for certainty $(M=42.419)$ is lower than for uncertainty $(M=$ 

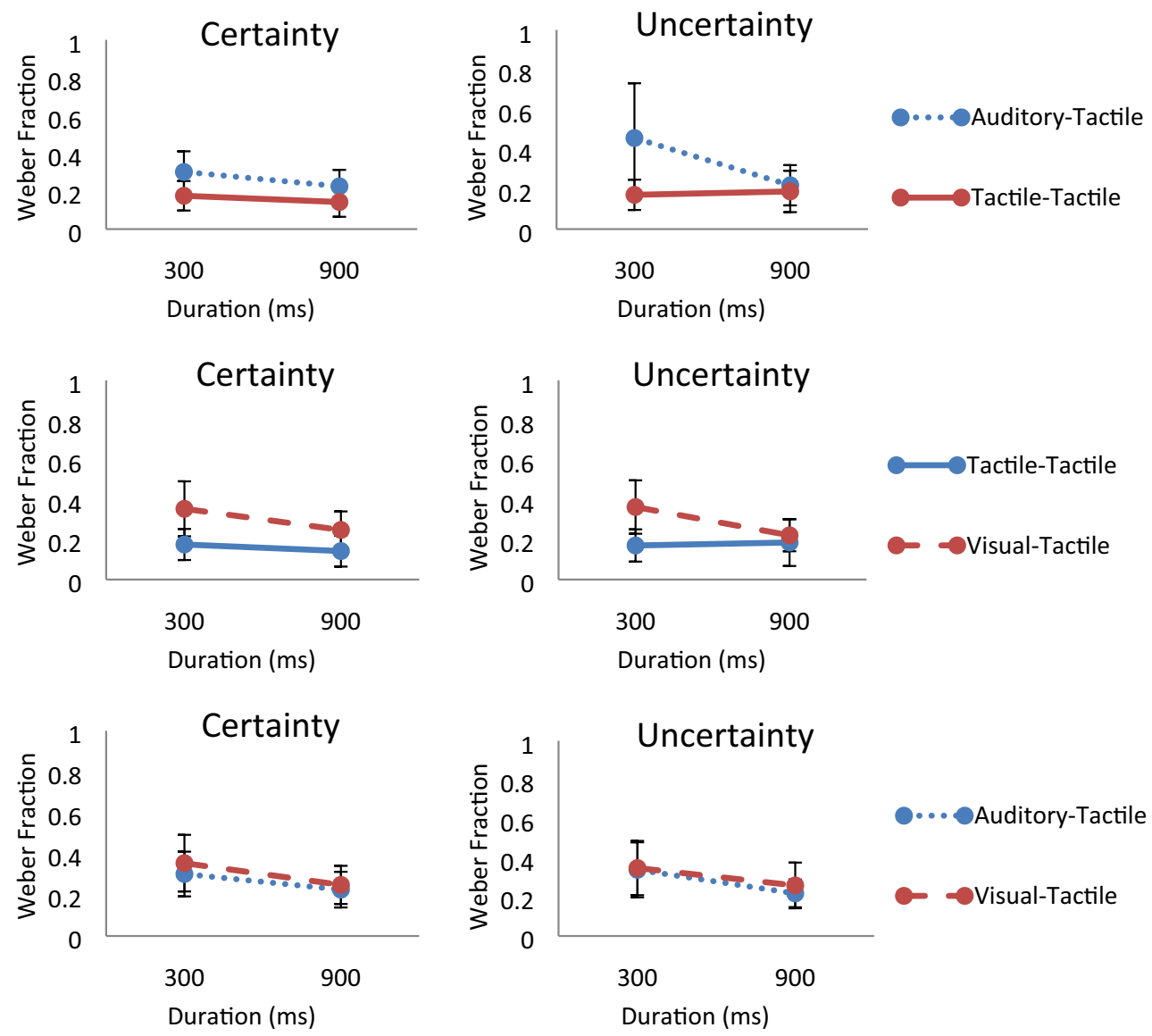

Fig. 5 Weber fraction in the TT versus AT (upper panel), TT versus VT (middle panel), and AT versus VT (lower panel) conditions under the certainty and uncertainty conditions in Experiment 3. Bars represent the standard error

66.647). There was a significant interaction between modality and certainty, $F(1,11)=13.060, p<.05, \eta_{\mathrm{p}}^{2}=.543$, and between certainty and duration, $F(1,11)=4.871, p<.05$, $\eta_{\mathrm{p}}^{2}=$ .307. The modality difference occurred in the uncertainty condition where AT intervals are perceived as longer than VT intervals. Moreover, at $900 \mathrm{~ms}$, the mean constant error is lower under certainty $(M=45.685)$ than under uncertainty $(M=$ 89.563), while there is no such difference at $300 \mathrm{~ms}$.

\section{Discussion of Experiment 3}

In the AT versus TT condition, and in the VT versus TT condition, the intramodal intervals were better discriminated than the intermodal interval. In both cases, the modality by duration interaction was significant. The Weber fraction in the TT condition remained constant from 300 to $900 \mathrm{~ms}$, but in the intermodal conditions, there is a decrease of the fraction at 900 ms. Moreover, the uncertainty about the first marker affected the overall level of performance when TT and AT intervals were used, but not when TT and VT intervals were used. When both intermodal intervals (VT and AT) are compared, only the duration effect is significant, with a decrease of the Weber fraction at $900 \mathrm{~ms}$.
For the constant error, there are two main findings of interest. First, there are more long responses in AT than in TT. This difference, however, is observable in both the certainty and uncertainty conditions; it cannot, therefore, be explained by a direct comparison of the interval length in each condition. In the portion of the experiment dedicated to intermodality (AT vs. VT), there is a significant Duration $\times$ Modality interaction. The VT intervals are clearly perceived as shorter than the AT intervals. This finding is consistent with a report of Grondin and Rousseau (1991) where, when 250-ms TT, AT, and VT intervals were compared (with an uncertainty on the modality of the first marker), the probability of responding long was .59 in AT and .43 in VT (.48 in TT). This last finding may be interpreted as an effect of reaction time for detecting auditory and visual signals, the faster reaction to auditory signals meaning that accumulation of pulses occurs earlier.

\section{General discussion}

In each portion of each of the three experiments, the difference threshold was measured at 300 and $900 \mathrm{~ms}$. Although there are only two different standard durations for each marker-type 
Certainty

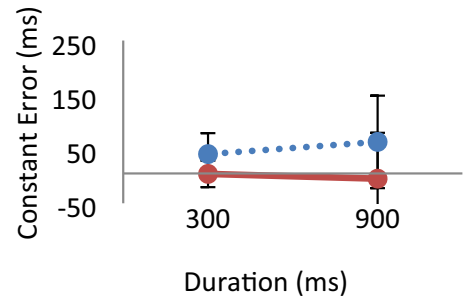

Certainty

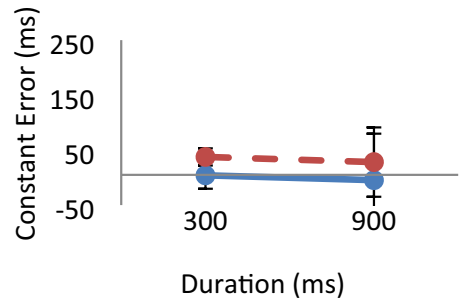

Certainty

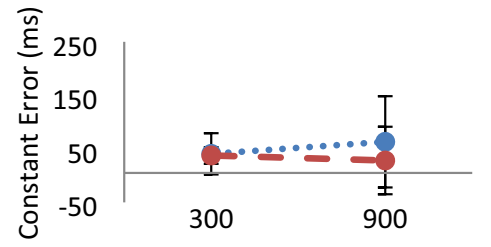

Duration (ms)
Uncertainty

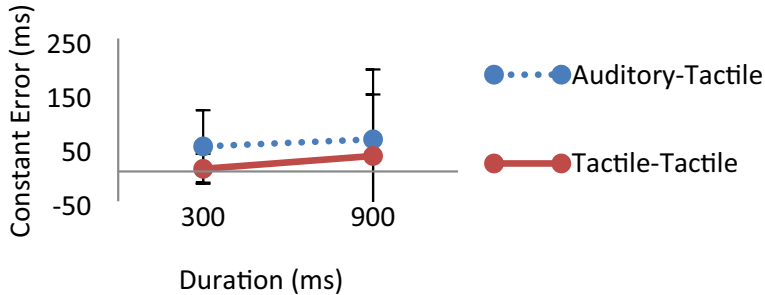

Uncertainty

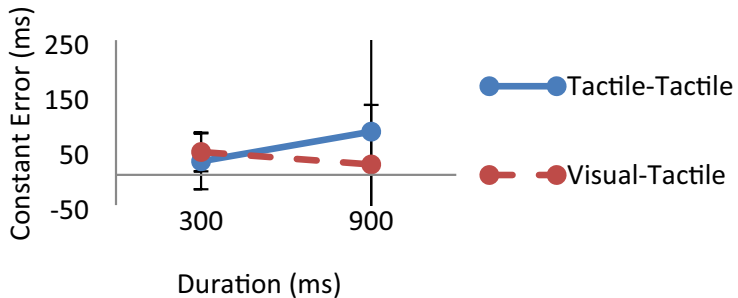

Uncertainty

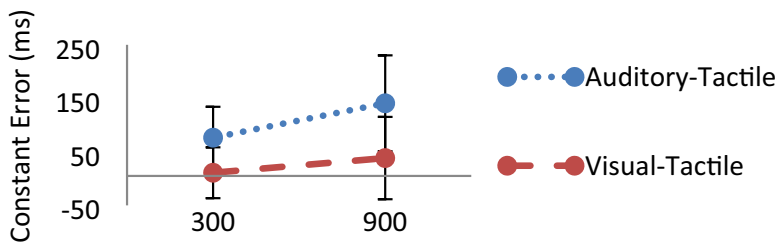

Duration (ms)

Fig 6 Constant error (in ms) in the TT versus AT (upper panel), TT versus VT (middle panel), and AT versus VT (lower panel) conditions under the certainty and uncertainty conditions in Experiment 3. Bars represent the standard error

condition, it is possible to look at a fundamental issue in the field of time perception, namely the stability of the Weber fraction in the different modality conditions (Grondin, 1993, 2014a; Rousseau et al., 1983). Strictly speaking, the Weber law indicates that the difference threshold should increase proportionally as a function of the magnitude of sensory stimulation; in other words, the Weber fraction, or scalar property (Gibbon, 1977), should remain constant (Grondin, 2001).

Overall, in all three intramodal conditions, AA (Experiment 1), VV (Experiment 2), and TT (Experiment 3), the Weber fraction at 300 and $900 \mathrm{~ms}$ remained approximately constant. This was true under both the certainty and uncertainty conditions. Note, however, that, in the case of AA intervals, a closer look at the Weber fraction reveals that the fractions were even lower at 300 than at $900 \mathrm{~ms}$. Such a finding seems to indicate that the processing of very brief intervals in the auditory modality is extremely efficient, maybe because of the frequent need to process rapid successions of sounds in speech or in music. This finding is less surprising considering that in Grondin (2010) the Weber fraction for the discrimination of empty auditory intervals is lower at 200 than at 1,000 ms. In addition, the discrimination was much better in AA (Experiment 1) than in VV (Experiment 2) or TT (Experiment 3). The superiority of temporal auditory processing over visual auditory processing is well documented (for a review, see Grondin, 2003) and is consistent with the idea of an auditory dominance in temporal processing (Walker \& Scott, 1981).

As for the nonauditory intramodal intervals, the performance in the certainty condition is slightly better in TT than in VV, but are about the same in the uncertainty conditions. In Grondin \& Rousseau et al. (1991), which involved 250-ms intervals, discrimination was reported to be slightly better in VV than in TT in the certainty condition, but was about the same when there was uncertainty on the first marker. Discrimination was also reported to be slightly better in VV than in TT at $250 \mathrm{~ms}$, but not at 1,000 ms (see Grondin, 2003).

In the six intermodal conditions used in the present investigations, the Weber fractions were much higher at 300 than at $900 \mathrm{~ms}$. The decrease of the Weber fraction with longer intervals is compatible with the generalized form of Weber's law. This means that the relative importance of nontemporal variance, compared with time-based variance, in the processing of time intervals, is higher at $300 \mathrm{~ms}$. More specifically, the 
temporal-based variance may well increase proportionally as intervals get longer, as indicated by the scalar property of pacemaker-counter models. Assuming that the nontemporal noise remains the same (constant) at 300 and $900 \mathrm{~ms}$, the importance of the nontemporal variance, in comparison with the temporal-based variance, would then decrease with longer intervals. Consequently, the increased Weber fractions with brief intervals in intermodality conditions would result from the nontemporal variance caused by some properties of intermodality.

In Mayer et al. (2014), in the AV, VA, TA, and AT conditions, the Weber fraction decreases from about $30 \%$ at $300 \mathrm{~ms}$ to about $20 \%$ at $900 \mathrm{~ms}$. In other words, a quite similar pattern of results was observed in this experiment and in the present study. Note, however, that in the VT and TV conditions of Mayer et al., the Weber fraction remained around 30\%, while in the present study the Weber fractions were lower at $900 \mathrm{~ms}$ than at $300 \mathrm{~ms}$ in TV (Experiment 2) and VT (Experiment 3). Moreover, it is noteworthy that the overall decrease of the intermodality effect with longer intervals is not compatible with the report of Rousseau et al. (1983). In this article (Experiment 3), the difference between the discrimination levels in AA and VV and the discrimination levels in $\mathrm{AV}$ and $\mathrm{VA}$, at $250 \mathrm{~ms}$, was maintained with intervals in the range of $1,000 \mathrm{~ms}$. In other words, there seem to be some experimental conditions, as in VT and TV in Mayer et al. (2014) and Rousseau et al. (1983) where Weber's law, even in its strict form, holds. Note however that at $100 \mathrm{~ms}$, the data of Mayer et al. indicate, compared with $300 \mathrm{~ms}$, an increase of the Weber fraction in VT and TV conditions.

The present study suggests that the generalized form of Weber's law is suitable for each of the six intermodal types of time intervals and that nontemporal noise is at play. For understanding the problem caused by intermodality, it is necessary to try to identify the nature of this nontemporal noise. Let us assume that the temporal mechanism responsible for time keeping is central (i.e., is the same whatever the signals used to mark an empty interval, so that the time-based variance is the same for all marker types). One explanation for the nontemporal noise would be the properties of the signals themselves. The clarity of signals originating from an auditory source would explain the high discrimination level in AA, assuming that there is less clarity from tactile or from visual signals for marking time. However, as noted in the introduction, any intermodal interval involving an auditory marker, first or second, should lead to better discrimination than any nonauditory intramodal condition (TT or VV), which is clearly not the case. Maybe the advantage of the TT and VV conditions comes from the repetition of the signals, assuming that the clarity of the second one would be improved by the passage of the first one; such a potential benefit would not be possible in intermodal conditions. If that is correct, this would mean that the second marker accounts for a larger proportion of the nontemporal variance than the first marker. In such a case, when an intermodal interval ends with an A signal, performance should be better than when it ends with a $\mathrm{T}$ or $\mathrm{V}$ signal, which is apparently not the case in Mayer et al. (2014), in Rousseau et al. (1983), and in the present experiments. On the other hand, it cannot be excluded that the processing of the second signal benefits from the previous arrival of an identical signal, in intramodal conditions, from some prior entry effect (Posner, 1978). This second signal would be detected faster, which might explain why the constant error is lower in intramodal than in intermodal conditions on many occasions in the three experiments.

The nontemporal noise in intermodality might be due to the need to shift attention from one sensory modality to another one, as indicated by some electrophysiological evidence (Gontier, Hasuo, Mitsudo, \& Grondin, 2013). Such an attentional effect should have been magnified by the introduction of uncertainty on the sensory origin of the first marker. Interestingly, there was no overall effect of uncertainty on the discrimination levels, neither in the intramodal nor in the intermodal conditions. Maybe that uncertainty on the second marker, instead of on the first one (i.e., during the processing of the intervals), would have had more impact on the attentional processes and, consequently, on the discrimination level. However, the overall discrimination levels in the uncertainty conditions, first versus second marker, were roughly the same in Grondin \& Rousseau (1991), where 220-ms versus 280-ms intervals were compared. This nonsignificant effect does not mean that there is no specific attentional noise in the processing of temporal information when intermodal intervals mark time, but this potential attentional effect on discrimination levels is not related to any fluctuation in the attentional preparation that could have served an efficient marking of the intervals.

The introduction of an uncertainty condition was expected to allow for a series of direct comparisons of the perceived duration in the different marker-type conditions. As indicated above, there are several cases where the intramodal intervals are perceived as shorter than intermodal intervals, which was interpreted as an effect due to the efficiency in detecting the second marker of an intramodal interval. The experiments also provided occasions to directly compare the perceived duration of intermodal intervals. There were no significant differences between the TA and VA intervals (Experiment 1) and between the AV and TV intervals (Experiment 2). However, in Experiment 3, the AT intervals were perceived as longer than the VT intervals. This might be caused by the possibility that participants let the trace of visual signals fade before undertaking the time-keeping activity. This hypothesis, though, is unlikely if we consider that a similar strategy would have been at play in Experiment 1 (TA vs. VA), but no difference was found between these conditions. Another explanation could be related to the fact that the reaction time to an auditory signal 
is faster than the reaction time to a visual signal (Giray \& Ulrich, 1993; Keele, 1986). Consequently, the time-keeping activity - namely, the period of accumulation of pulses, in the perspective of a pacemaker-accumulator process (Rammsayer \& Ulrich, 2001) - would begin earlier in AT than in VT. Indeed, Mayer et al. (2014) reported that intervals with an auditory onset (AV and AT) are perceived to be longer than intervals with an auditory offset (VA and TA).

This three-experiment investigation does not permit to close the door on the debate as to whether or not there is a unique, central time-keeping mechanism that is solicited, whatever the sensory conditions marking time intervals to be estimated (Hartcher-O'Brien, Di Luca, \& Ernst, 2014). The systematically better performances of intramodal intervals, compared with intermodal intervals, observed at $300 \mathrm{~ms}$, could lead to the conclusion that there is a specific processor for intramodal intervals, and an aspecific, central, processor for taking care of the time keeping of intermodal intervals (Grondin \& Rousseau, 1991). Within such a view, the different discrimination levels when intramodal conditions are compared would be related to the local (within each modality) level of efficiency for processing temporal information. Other authors, along the line of the classical pacemakeraccumulator model, rather posit that there is a single pacemaker, but the switch-accumulator system is specific to each modality (L. Rousseau \& Rousseau, 1996).

However, at $900 \mathrm{~ms}$, in most cases, we can observe that the intramodal versus intermodal differences tend to fade: The Weber fractions are close to constant in intramodal conditions, but are significantly lower at 900 than at $300 \mathrm{~ms}$ in intermodal conditions. Assuming that the different discrimination levels are caused by the nontemporal noise in the discrimination process - the sources of this noise being discussed abovethe question remains open as to the nature of this central timekeeping process. The neuroscience literature indicates that the primary auditory cortex may have a supramodal role in temporal information processing (Kanai et al., 2011; Mioni, Grondin, et al., 2016b; Stauffer, Haldemann, Troche, \& Rammsayer, 2012). If time keeping requires that sensory signals marking time have to be transformed into an auditory code, it is difficult to explain why the discrimination of an intermodal interval involving one auditory marker is lower than the discrimination of intramodal intervals involving two nonauditory markers (as in VV or TT). It is also known that the right posterior parietal cortex contributes to the duration discrimination process of both intramodal and intermodal intervals (Mioni, Grondin, Mapelli, \& Stablum, 2018). It is therefore reasonable to assume that a common pathway is taken for processing temporal information, whatever the sensory origin of the signals marking the time intervals to be estimated. What remains to be determined is where exactly are located the sources of nontemporal noise in conditions involving the discrimination of brief intermodal intervals.
Acknowledgements This study is part of the Doctoral thesis of L.A. This study was supported by a research grant (Grant No. RGPIN-2016-05028) from the Natural Sciences and Engineering Research Council of Canada to S.G. We would like to thank Célyne Bastien for her comments on this project and one anonymous reviewer for the comments on a previous version of this article. Correspondence should be addressed to Simon Grondin, École de psychologie, 2325 rue des Bibliothèques, Université Laval, Québec, Qc, Canada, G1V 0 A6 (E-mail: simon.grondin@psy.ulaval.ca).

\section{References}

Behar, I., \& Bevan, W. (1961). The perceived duration of auditory and visual intervals: Cross-modal comparison and interaction. The American Journal of Psychology, 74, 17-26.

Bueti, D. (2011). The sensory representation of time. Frontiers of Integrative Neuroscience, 5. doi:https://doi.org/10.3389/fnint.2011. 00034

Block, R. A., \& Zakay, D. (2008). Timing and remembering the past, the present, and the future. In S. Grondin (Ed.), Psychology of time (pp. 367-394). Bingley, England: Emerald Group.

Fraisse, P. (1952). La perception de la durée comme organisation du successif. Mise en évidence expérimentale. L'Année Psychologique, 52, 39-46.

Gamache, P.-L., \& Grondin, S. (2010). The life span of time intervals in reference memory. Perception, 39, 1431-1451.

Gibbon, J. (1977). Scalar expectancy theory and Weber's law in animal timing. Psychological Review, 84, 279-325.

Gibbon, J., Church, R. M., \& Meck, W. H. (1984). Scalar timing in memory. In J. Gibbon \& L. Allan (Eds.), Annals of the New York Academy of Sciences: Vol. 423. Timing and time perception (pp. 5277). New York: New York Academy of Sciences. doi:https://doi.org/ 10.1111/j.1749-6632.1984.tb23417.x

Giray, M., \& Ulrich, R. (1993). Motor coactivation revealed by response force in divided and focused attention. Journal of Experimental Psychology: Human Perception \& Performance, 19, 1278-1291.

Goldstone, S., \& Goldfarb, J. L. (1964). Direct comparisons of auditory and visual durations. Journal of Experimental Psychology, 67(5), 483-485.

Goldstone, S., \& Lhamon, W. T. (1972). Auditory-visual differences in human temporal judgment. Perceptual and Motor Skills, 34(2), 623-633.

Goldstone, S., \& Lhamon, W. T. (1974). Studies of auditory-visual differences in human time judgment: I. Sounds are judged longer than lights. Perceptual \& Motor Skills, 39, 63-82.

Gontier, E., Hasuo, E., Mitsudo, T., \& Grondin, S. (2013). EEG investigations of duration discrimination: The intermodal effect is induced by an attentional bias. PLOS ONE, 8(8): e74073. doi:https://doi.org/ 10.1371/journal.pone.0074073.

Grondin, S. (1993). Duration discrimination of empty and filled intervals marked by auditory and visual signals. Perception \& Psychophysics, 54, 383-394.

Grondin, S. (2001). From physical time to the first and second moments of psychological time. Psychological Bulletin, 127, 22-44.

Grondin, S. (2003). Sensory modalities and temporal processing. In H. Helfrich (Ed.), Time and Mind II: Information processing perspectives (pp. 75-92). Ashland, OH: Hogrefe \& Huber.

Grondin, S. (2005). Overloading temporal memory. Journal of Experimental Psychology: Human Perception and Performance, $31,869-879$.

Grondin, S. (2008). Methods for studying psychological time. In S. Grondin (Ed.), Psychology of time (pp. 51-74). Bingley, England: Emerald Group. 
Grondin S. (2010). Unequal Weber fraction for the categorization of brief temporal intervals. Attention, Perception, \& Psychophysics, 72, $1422-1430$

Grondin, S. (2014a). About the (non)scalar property for time perception. In H. Merchant \& V. de Lafuente (Eds.), Advances in Experimental Medicine and Biology: Vol. 829. Neurobiology of interval timing (pp. 17-32) New York: NY: Springer.

Grondin, S. (2014b). Why studying intermodal duration discrimination matters. Frontiers in Psychology: Perception Science, 5, 628. doi: https://doi.org/10.3389/fpsyg.2014.00628

Grondin, S., Gamache, P.-L., Tobin, S., Bisson, N., \& Hawke, L. (2008). Categorization of brief temporal intervals: An auditory processing context may impair visual performances. Acoustical Science \& Technology, 29, 338-340.

Grondin, S., Ivry, R., Franz, E., Perreault, L., \& Metthé, L. (1996). Markers' influence on the duration discrimination of intermodal intervals. Perception \& Psychophysics, 58, 424-433.

Grondin, S., Ouellet, B., \& Roussel, M.-E. (2001). About optimal timing and stability of Weber fraction for duration discrimination. Acoustical Science \& Technology, 22, 370-372.

Grondin, S., Ouellet, B., \& Roussel, M.-E. (2004). Benefits and limits of explicit counting for discriminating temporal intervals. Canadian Journal of Experimental Psychology, 58, 1-12.

Grondin, S., \& Rousseau, R. (1991). Judging the relative duration of multimodal short empty time intervals. Perception \& Psychophysics, 49, 245-256.

Grondin, S., Roussel, M.-E., Gamache, P.-L., Roy, M., \& Ouellet, B. (2005). The structure of sensory events and the accuracy of judgments about time. Perception, 34, 45-58.

Hartcher-O'Brien, J., Di Luca, M., \& Ernst, M. O. (2014). The duration of uncertain times: Audiovisual information about intervals is integrated in a statistically optimal fashion. PLOS ONE 9(3), e89339. doi: https://doi.org/10.1371/journal.pone.0089339

Hocherman, S., \& Ben-Dov, G. (1979). Modality-specific effects on discrimination of short empty time intervals. Perceptual \& Motor Skills, 48, 807-814.

Kanai, R., Lloyd, H., Bueti, D., \& Walsh, V. (2011). Modalityindependent role of the primary auditory cortex in time estimation. Experimental Brain Research, 209, 465-471.

Keele, S. W. (1986). Motor control. In K. R. Boff, L. Kaufman, \& J. P. Thomas (Eds.), Handbook of Perception and Human Performance: Vol. 2. Cognitive processes and performance (pp. 30-1-30-60). Toronto, Canada: Wiley.

Kuroda, T., Hasuo, E., Labonté, K., Laflamme, V., \& Grondin, S. (2014). Discrimination of two neighboring intramodal and intermodal empty time intervals marked by three successive stimuli. Acta Psychologica, 9, 134-141.

Mayer, K. M., Di Luca, M.. \& Ernst, M. O. (2014). Duration perception in crossmodally-defined intervals. Acta Psychologica, 147, 2-9.
Mioni, G., Grassi, M., Tarantino, V., Stablum, F., Grondin, S., \& Bisiacchi, P. S. (2016a). The impact of a concurrent motor task on auditory and visual temporal discrimination tasks. Attention, Perception, \& Psychophysics, 78, 742-748.

Mioni, G., Grondin, S., Forgione, M., Fracasso, V., Mapelli, D. \& Stablum, F. (2016b). The role of primary auditory and visual cortices in temporal processing: A tDCS approach. Behavioural Brain Research, 313, 151-157.

Mioni, G., Grondin, S., Mapelli, D., \& Stablum, F. (2018). A tRNS investigation of the sensory representation of time. Scientific Reports, 8, 10364, doi:https://doi.org/10.1038/s41598-018-28673-7

Penney, T. B., Gibbon, J., \& Meck, W. H. (2000). Differential effects of auditory and visual signals on clock speed and temporal memory. Journal of Experimental Psychology: Human Perception and Performance, 26, 1770-1787.

Posner, M. I. (1978). Chronometric explorations of the mind. Hillsdale, NJ: Erlbaum.

Rammsayer, T., \& Ulrich, R. (2001). Counting models of temporal discrimination. Psychonomic Bulletin \& Review, 8, 270-277.

Rousseau, L., \& Rousseau, R. (1996) Stop-reaction time and the internal clock. Perception \& Psychophysics, 58, 434- 448.

Rousseau, R., \& Kristofferson, A. B. (1973). The discrimination of bimodal temporal gaps. Bulletin of the Psychonomic Society, 1, 115116.

Rousseau, R., Poirier, J., \& Lemyre, L. (1983). Duration discrimination of empty time intervals marked by intermodal pulses. Perception \& Psychophysics, 34, 541-548.

Stauffer, C. C., Haldemann, J., Troche, S. J., \& Rammsayer, T. H. (2012). Auditory and visual temporal sensitivity: Evidence for a hierarchical structure of modality-specific and modality-independent levels of temporal information processing. Psychological Research, 76, 20 31.

Ulrich, R., Nitschke, J., \& Rammsayer, T. (2006). Crossmodal temporal discrimination: Assessing the predictions of a general pacemakercounter model. Perception \& Psychophysics, 68, 1140-1152.

van Noorden, L. (1975). Temporal coherence in the perception of tone sequences (Unpublished doctoral dissertation). Eindhoven University of Technology, Eindhoven, Netherlands. doi:https://doi. org/10.6100/IR152538

Walker, J. T., \& Scott, K. J. (1981). Auditory-visual conflicts in the perceived duration of lights, tones and gaps. Journal of Experimental Psychology: Human Perception and Performance, 7, 1327-1339.

Wearden, J. H., Edwards, H., Fakhri, M., \& Percival, A. (1998). Why "sounds are judged longer than lights": Application of a model of the internal clock in humans. Quarterly Journal of Experimental Psychology, 51B, 97-120.

Publisher's note Springer Nature remains neutral with regard to jurisdictional claims in published maps and institutional affiliations. 